\title{
ENTRE A FRONTEIRA DA CORRUPÇÃO: MILLÔR E A NOVA REPÚBLICA
}

\author{
PÂMERA FRANCIELI CORREAA PEREIRA (SEED - PR) ${ }^{1}$
}

\begin{abstract}
RESUMO: Este artigo tem como objetivo a analisar duas charges que abrangem o discurso de Millôr Fernandes sobre a Nova República (1985 - 1990) considerando a relação interdiscursiva presente no dizer do autor. As análises terão como base teórica a Teoria do Discurso de linha francesa, tendo como principal teórico Michel Pêcheux, dentre outras fontes necessárias para embasar as condições de produção do corpus, como Hugon (2009). Os objetivos que norteiam esta pesquisa se resumem em dar a conhecer a relação interdiscursiva no dizer de Millôr, no tocante a recuperação de dizeres outros; compreender que Millôr é porta-voz de um discurso que se transpõe no viés do humor sobre a política da Nova República (1985 - 1990); e buscar estabelecer pontos análogos quanto a uma política do passado e do presente. Sob o exercício de retomadas discursivas, compreender que há uma região de fronteira entre uma política honesta e a prática de uma irresponsabilidade administrativa por parte de políticos que regem em benefício próprio. O interdiscurso é o conceito mobilizado para as análises das charges eleitas neste corpus que, em consonância com as condições de produção, possibilita evocar efeitos de sentidos a partir de cada enunciado, bem como de cada imagem caricata que é analisada como fator de significação, o qual evoca um discurso. Por fim, o que justifica a temática deste trabalho é a cadência do dizer de Millôr sobre a acuidade do tema que envolve a política, e por considerar que esta rege a sociedade e impera sobre ela.
\end{abstract}

PALAVRAS-CHAVE: Millôr. Nova República. Interdiscurso.

ABSTRACT: This article aims to analyze two cartoons that cover Millor Fernandes' discourse on the New Republic (1985 - 1990) considering the interdiscursive relationship present in the author's words. The analyzes will have as theoretical basis the Discourse Theory of French line, having as main theoretician Michel Pêcheux, among other sources necessary to support the conditions of production of the corpus, as Hugon (2009). The objectives that guide this research are summarized in making known the interdiscursive relationship in the words of Millôr, regarding the recovery of other words; to understand that Millor is the spokesman for a discourse that transposes itself in the bias of humor on the politics of the New Republic (1985 - 1990); and seek to establish similar points regarding a policy of the past and the present. Under the exercise of discursive resumes, understand that there is a border region between an honest policy and the practice of administrative irresponsibility by politicians who rule for their own benefit. Interdiscourse is the concept used to analyze the cartoons chosen in this corpus, which, in line with the conditions of production, makes it possible to evoke effects of meanings from each statement, as well as from each cartoon image that is analyzed as a factor of significance, the which evokes a speech. Finally, what justifies the theme of this work is the cadence of saying by Millôr on the accuracy of the theme that involves politics, and considering that it governs society and rules over it.

KEYWORDS: Millôr. New Republic. Interdiscourse.

\section{INTRODUÇÃO}

Este trabalho tem como objeto de pesquisa o discurso de Millôr Fernandes sobre a Nova República e a relação interdiscursiva presente no seu dizer. Para a práxis deste empreendimento, lançou-se mão de um recorte de charges retiradas do livro "Diário da Nova

\footnotetext{
${ }^{1}$ Docente da Secretaria Estadual de Educação do Paraná (SEED - PR). Mestra em Letras pela Universidade Estadual do Oeste do Paraná. E-mail: pamerapr@hotmail.com
} 


\section{$=$ TRAMA $=$}

República - Vol. 2", de Millôr Fernandes (1988), as quais foram norteadoras e compuseram o corpus que fomentou a análise. O delineamento histórico referente às condições de produção do corpus perpassa o período entre 1985 e 1990, que se referem ao governo Sarney, período antecedido pela Ditadura Militar, a qual precede o cenário que delimita o conteúdo das charges elencadas para a investigação.

Este artigo apresenta duas análises acerca de duas charges de Millôr, a fim de colocar em discussão a política brasileira. A escolha do corpus se deu pela incidência de provocações discursivas que emergem das produções de Millôr sobre o fazer político na Nova República e a relação que há entre o passado e o presente, sob a ótica do percurso histórico de governança no Brasil. Pressupor que existam pontos análogos do antes (Ditadura Militar), do depois (Nova República de 1985 - 1990) e do agora é o que instiga a diligência para tratar do assunto, no que compreende os efeitos de sentido produzidos, inerente às charges, que manifestam uma perspectiva de realidade. O recorte do corpus assegura a trajetória para a análise e rumos da pesquisa.

A justificativa deste trabalho está para as facetas do discurso de Millôr que revelam as contingências da política brasileira, no que diz respeito à forma de governar daqueles que estão no poder que afirmam que cuidarão dos interesses do povo e deveriam cumprir fielmente as ordenações legais que implicam diretamente na vida de cada cidadão brasileiro. A pesquisa se pauta pela acuidade do tema que envolve a política, por considerar que ela rege a sociedade e impera sobre esta o fortuito ou a aflição que é estar sob o jugo do poder executivo de um país e, portanto, qualquer que seja o olhar lançado para compreender o sistema que organiza a vida social de uma nação, bem como atentar para as ações dos governantes no exercício da função, uma vez que se colocaram a serviço do povo, a saber, tem o seu teor de contundência e é oportuno para a apreciação.

Deste modo, a partir do dizer do autor sobre a Nova República é que será alicerçado o caminho para propor um olhar para o processo interdiscursivo presente nos enunciados das charges a ser compartilhado neste artigo. Considerando o fato de que Millôr se utiliza do humor para dizer acerca do ensejo político do Brasil entre 1985 e 1990 e que o faz recapturando dizeres, entende-se que o tema deste artigo é o humor político na perspectiva do interdiscurso.

Para as análises, serão levados em conta como elementos de significação das charges tanto os enunciados, que dizem respeito à materialidade discursiva, quanto as imagens caricatas produzidas pelo autor e que são porta-voz de um discurso. Considerando que o discurso é o alvo que desencadeia o movimento analítico em torno do dito e do já-dito e de tudo o que envolve a concepção e constituição de um dizer, este trabalho se vale da atenção ao sujeito que enuncia com a subjetivação, as condições de produção do ato enunciativo, os atravessamentos ideológicos inerentes ao discurso, no tocante à inscrição do sujeito em uma dada formação discursiva, bem como para a materialização da língua, responsável por transpor o discurso.

A teoria que dará luz às análises do recorte do corpus é a Teoria do Discurso de linha francesa, além do aparato de autores que contribuem para o embasamento do conteúdo histórico a ser recuperado para apresentar as condições de produção das charges selecionadas para compor o corpus e dar suporte para seguir com as considerações acerca do entrelaçamento entre as produções de Millôr, a história, a língua e a prática analítica do discurso. No que diz respeito à metodologia, trata-se de uma pesquisa qualitativa, que incorre no método investigativo de base discursiva, o qual deve validar o percurso da investigação que culmina nas análises das charges de Millôr. 


\section{$=$ TRAMA $=$}

As duas análises presentes neste artigo contornam as charges eleitas para a investigação, em que são mobilizados os conceitos da Teoria do Discurso, no que concerne ao sujeito, à língua e à história, detendo-se nas condições de produção, para dar vazão à construção do efeito de sentido de cada uma, ao passo que compreendem o humor político, o qual compreende ao objeto de estudo. Para tanto, serão tecidas reflexões em que devem ser apontadas as devidas correlações dos efeitos da discursividade de Millôr a respeito da política da Nova República (1985 - 1990) com os moldes da política que se pratica atualmente.

Em consonância com a discussão sobre a temática política brasileira, é possível conhecer a relação interdiscursiva do dizer de Millôr, no tocante à recuperação de dizeres outros, sobre a política da Nova República, tendo Millôr como porta-voz de um discurso que se transpõe no viés do humor e a denúncia da política do passado. Sob um exercício de retomadas discursivas, o interdiscurso é o conceito da Teoria do Discurso que vai permear esta pesquisa, enriquecendo o processo de análise do recorte das charges que constituem o corpus e os aspectos peculiares ao discurso de Millôr que despontam na materialidade discursiva de suas produções e que devem merecer um teor considerável para o desenvolvimento das análises ao longo do artigo.

Enfim, o escopo deste trabalho é o de considerar os efeitos de sentido do discurso de Millôr, a partir de reflexões acerca das charges que o autor produz sobre a política da Nova República (1985 - 1990), que perpassa o cotidiano de cidadãos inseridos numa conjuntura política de reincidência na corrupção. Em especial, atentar para os discursos que são recuperados no ato de enunciação, no chamado processo de interdiscursividade, que atuam na construção dos efeitos de significação, dadas as suas condições de produção, que compreendem o âmbito político-social e que delatam as relações de poder no movimento da história. O intento é buscar, por meio da análise do corpus, a relação interdiscursiva do dizer do autor com a iminência do discurso que se vale do humor irônico e satírico, talhado na subjetivação e assujeitamento de um jornalista que constrói o dizer fabricando sentidos a partir da fragilidade política do país, levando-se em conta que o humor é capaz de tornar assuntos hostis em brincadeiras que configuram um pensamento coletivo.

\section{GOVERNO DA PIRATARIA}

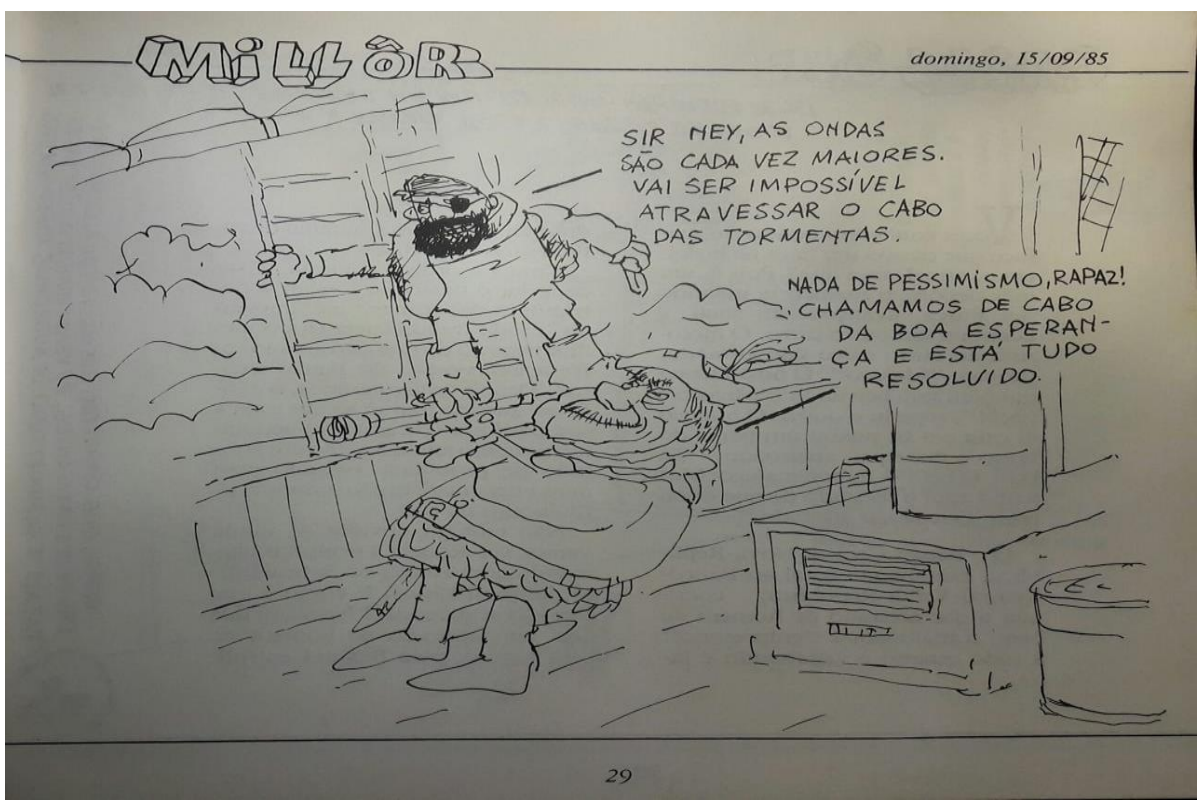




\title{
$=$ TRAMA $=$
}

O enunciado desta charge é "Sr. Ney, as ondas são cada vez maiores. Vai ser impossivel atravessar o Cabo das Tormentas", "nada de pessimismo, rapaz! Chamamos de Cabo da Boa Esperança e está tudo resolvido". Nesta charge, Millôr alude interdiscursivamente ao universo da pirataria. Ele traz caricatas as personagens como piratas em um navio que passa por instabilidades devido às turbulências provocadas pelas altas ondas no mar. Os homens, na imagem, representam os governantes, sendo um deles o presidente Sarney, cujo navio simboliza o governo que está sob seus mandos e desmandos, e as ondas que o desestabilizam caracterizam as questões a serem resolvidas pelo governo e que não são. O que ocorre é que Millôr compara o governo a um navio pirata regido por marinheiros piratas, ou, governantes piratas.

Quanto à formação imaginária que, segundo Pêcheux (1997), se refere ao resultado dos processos discursivos reguladores de imagens anteriores ao discurso, em relação ao que compreende um pirata, há uma questão histórica que dá conta de fundamentar, ou seja, há uma imagem já estabelecida do que é a pirataria, de quais são as atividades que ela exerce e quais são os atravessamentos ideológicos que carregam em sua significação. Para chegar a um entendimento do que o interdiscurso da pirataria retoma para construir os efeitos de sentido no acontecimento discursivo enunciado por Millôr, recorre-se a uma pesquisa sobre a história dos piratas, na qual alguns excertos expõem o seguinte:

\begin{abstract}
Na verdade, a pirataria não era propriamente uma novidade na Europa daqueles notáveis tempos de expansão econômica e marítima. Tão antiga quanto a própria história da navegação, a pirataria se fez presente desde os tempos antigos, passando pelo Egito e Grécia até o império romano. Depois, durante a Idade Média, teve nos vikings nórdicos seus mais ferozes praticantes. Além deles, também ingleses, franceses, holandeses, irlandeses e árabes dedicaramse ao ofício pouco nobilitante de despojar de suas riquezas navios em alto-mar. [...] Apesar disso, houve época em que a atividade chegou a ser estimulada por vários governos. [...] Qualquer marinheiro que embarcasse num navio pirata sabia, por exemplo, que sem presa não haveria paga. Por isso, era uma gente disposta a tudo. Quando o capitão do navio finalmente conseguia arrebanhar a tripulação de que precisava para zarpar, estabelecia as regras para a divisão do produto do saque. Os interessados ficavam então sabendo que, terminada a pilhagem, as mercadorias seriam vendidas; calculado seu valor total, deduziamse as despesas de viagem (um terço era pago a quem havia financiado o, digamos, empreendimento) e o restante era repartido. Ao capitão, naturalmente, cabia a parte do tubarão - algo como um terço do produto do saque; os marinheiros de primeira viagem ficavam com os trocados (SUPER INTERESSANTE, 2016).
\end{abstract}

O universo da pirataria é reconhecido historicamente como uma realidade de espoliação e saques ilícitos a navios em alto mar. O que importa perceber é que um navio pirata sai para velejar com o objetivo de roubar outros navios, com o intento de utilizar os recursos materiais que não the pertencem e despojar a qualquer custo, ainda que seja necessário atentar contra a vida. Esta afirmativa coloca a condição de pirata como aquele que comete crimes de roubo e outros crimes mais graves, como o homicídio, se necessário for, para angariar toda sorte de riquezas de outro navio.

Pelo que expõe a história acerca da pirataria, pode-se depreender que a imagem de um pirata é concebida por uma dada formação imaginária, cuja concepção de significação desponta de processos discursivos anteriores e pelo que está formado e calcado ideologicamente e se manifesta nos discursos, a saber, um jogo de imagens constituído historicamente que vem para se integrar ao discurso enunciado, o qual incorre no já-dito. Trata-se das projeções que se tem acerca do dizer, do que é retomado e carregado de 


\section{$=$ TRAMA $=$}

sentido pré-existente. Sendo assim, a imagem que se tem de um pirata é relativa a um ladrão ou extorsor, que age para o benefício próprio em detrimento de qualquer benefício a outrem.

Ao lançar mão do interdiscurso da pirataria, uma vez que o presidente Sarney é comparado a um pirata, Millôr estabelece uma analogia entre a formação imaginária do que compreende a um pirata com o governo de Sarney. Condizentes com as ações de piratas, as quais remetem à apropriação ilícita do que pertence a outro, também estão as atitudes governamentais de Sarney ao ser retratado como um pirata em um navio que simboliza, interdiscursivamente, o seu governo. Ou seja, a política brasileira está sob o comando de quem rege para se beneficiar, extorquindo a nação e obtendo o que de valor a posição de presidente pode lograr.

Com este interdiscurso, Millôr coloca Sarney na posição daquele que usurpa, a partir do lugar social que ocupa, pois se utiliza do cargo de presidente da República para adquirir, aos moldes de um pirata, toda sorte de benefícios para si e para aqueles que trabalham sob sua liderança. Estes efeitos de sentido resultam de uma situação de injustiça por parte da governança e de falcatruas do governo em relação ao povo do qual se serve. Neste caso, a memória interdiscursiva suscitada por meio da materialidade discursiva e da imagem implica considerar os efeitos da pirataria, no que diz respeito à sua representação imoral, isto é, contrária à norma, por se tratar de cometer atos ilícitos, atribuindo analogamente o estereótipo ao presidente Sarney em seu governo. Em relação à memória e sua estruturação na língua, Pêcheux (2007, p. 52) afirma:

Tocamos aqui um dos pontos de encontro com a questão da memória como estruturação de materialidade discursiva complexa, estendida em uma dialética da repetição e da regularização: a memória discursiva seria aquilo que, face a um texto que surge como acontecimento a ler, vem restabelecer os 'implícitos' (quer dizer, mais tecnicamente, os pré-construídos, elementos citados e relatados, discursos-transversos, etc.) de que sua leitura necessita: a condição do legível ao próprio legível.

Em consonância com a citação acima, a memória discursiva restabelece implícitos ou pré-construídos em um ato de discurso que carece de uma investigação, pois cria uma conexão entre o discurso anterior e o momento do dizer, sendo que dá suporte para os efeitos de sentido evocados pelo interdiscurso, visto que é a estruturação de uma imagem já estabelecida que, ao ser suscitada pela formação imaginária, introduz nuances de significação a um discurso que irrompe fundado na formação discursiva do sujeito e na conjuntura de sua condição de produção.

A materialidade discursiva "Sir Ney, as ondas são cada vez maiores. Vai ser impossível atravessar o Cabo das Tormentas" permite depreender que as ondas do mar se referem às adversidades que o governo de Sarney precisa enfrentar, visto que as dificuldades não apontam para uma resolução simples e possível. O sujeito caricato que enuncia esse dizer integra a equipe da presidência e, diante de um cenário não favorável para a política da chamada Nova República, se acovarda ao dar-se conta do quão crítica é a situação de governança do Brasil, de tal forma que não consegue encontrar uma solução, uma vez que "as ondas são cada vez maiores" entende-se que a proporção dos problemas em que o país se configura parece impossível de ser acertada.

O enunciado "Vai ser impossível atravessar o Cabo das Tormentas" rememora o interdiscurso da história de descoberta do Cabo das Tormentas pelo navegador português Bartolomeu Dias, que batizou o cabo com este nome porque enfrentou tempo tempestuoso e mar agitado, que fizeram com que dificultasse a navegação. O Cabo das Tormentas, ao ser dobrado, mostrou a ligação entre o oceano Atlântico e o Índico, facilitando o acesso que liga à 


\section{$=$ TRAMA $=$}

Índia o que, posteriormente, ampliou as perspectivas de negócios para Portugal. Por analogia, o governo de Sarney encontra-se tal qual o mar que o navegador enfrentou e que supõe um quadro insatisfatório, gerando debilidades no comando de sua gestão governamental.

Todavia, Millôr interpõe, como resposta do caricato Sarney, um discurso suavizador cuja materialidade discursiva é "Nada de pessimismo, rapaz! Chamamos de Cabo da Boa Esperança e está tudo resolvido". Tal enunciado manifesta um teor manipulador por parte do presidente Sarney acerca das questões problemáticas que envolvem a política no Brasil durante o seu governo que, comparado à história da navegação de Portugal, em que o rei Dom Joao II renomeou o Cabo das Tormentas para Cabo da Boa Esperança, Portugal obteria vantagens comerciais, ao se utilizar dessa descoberta marítima, mudaria o discurso para um que fosse crédulo, para não perder os ganhos e vantagens que a posição de governante the proporciona. Quanto à história que envolve a navegação que resultou na descoberta do Cabo das Tormentas, o que consta é:

Em 3 de fevereiro de 1488, aos 34 graus de latitude, Bartolomeu finalmente avistou a tão sonhada 'esquina' da África. A travessia foi feita sob ferozes tempestades, o que inspirou o navegador a batizar o local de cabo das Tormentas. O nome, porém, teve vida curta. Em dezembro, dez meses após realizar a façanha, Bartolomeu aportou em Lisboa. O rei Dom João II, exultante com a nova rota comercial, preferiu deixar para a história um nome menos sombrio, e rebatizou o lugar como cabo da Boa Esperança (UOL, GRANDES NAVEGAÇÕES, 2019).

Do mesmo modo que o rei de Portugal ressignificou o nome do Cabo das Tormentas para Cabo da Boa Esperança, porque obteria vantagens e lucros, decidindo por silenciar as evidências e dificuldades que o local ofereceu ao navegador Bartolomeu Dias, também Sarney opta por não levar em conta as dificuldades que o Brasil enfrenta, as quais envolvem problemas financeiros e políticos da nação, em nome de seus interesses e possibilidades vantajosas. O interdiscurso provoca, assim, efeitos de sentido que remontam a um jogo de interesses e dissimulação por parte de quem tem o poder, em nome dos privilégios que resultam de atos coercitivos que acerca dos eventos, fatos e circunstâncias para angariar regalias.

Novamente, aparece o pronome de tratamento emprestado da Língua Inglesa "Sir" que, ao ser pronunciado com "Ney", forma o nome Sarney, que é referido, de modo sarcástico, à posição prestigiada do presidente. Isto implica considerar que, embora Sarney ocupe um cargo de notoriedade, é um governante que está aquém de sua posição, no que diz respeito ao cargo que possui, pois Millôr mistura o tratamento formal da Língua Inglesa com a redução do nome do presidente, ao apelido "Ney", desautorizando a formalidade que requer a figura de presidente da República, como um modo de subestimar Sarney, no trato com a língua, ainda que ele exerça uma posição de representatividade e autoridade no país.

A memória que se tem do que é a pirataria é recuperada pelo acontecimento discursivo produzido por Millôr, a fim de construir um efeito de que o governo de Sarney se assemelha à extorsão. Millôr é porta-voz de uma ideologia de oposição ao governo e, a partir da sua formação discursiva, usa do estereótipo da pirataria, que consiste em roubar e extorquir, para representar a política da Nova República, sob o domínio de Sarney que, mesmo diante das problemáticas políticas e financeiras do país, contorna as dificuldades mascarando e governando de acordo com os próprios interesses. 


\section{$=$ TRAMA $=$}

\section{A FALÁCIA DA PRIVATIZAÇÃO}

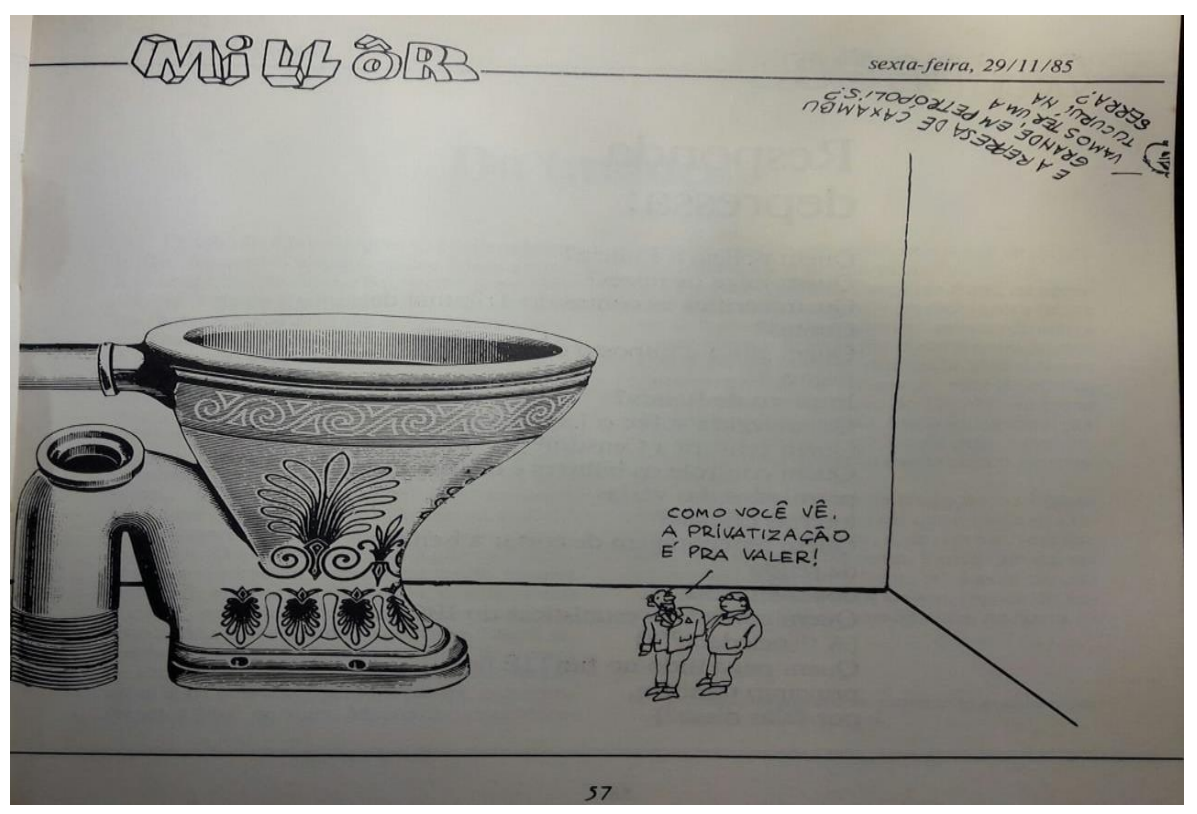

A charge acima estabelece uma relação interdiscursiva com a função da arte plástica, da atividade estética, do valor da beleza, da função lexical e da possibilidade de camuflar a realidade, por meio do discurso, para atingir o que pretende. Millôr se vale da imagem de uma privada ornamentada para, num processo de interdiscursividade, significar o quanto a privatização é uma maneira de gerir a nação.

O enunciado, representando um diálogo entre cidadãos comuns, em que uma personagem caricata diz "Como você vê, a privatização é pra valer!", cria um efeito de sentido que traduz a aceitação, no discurso, da privatização como um fenômeno que corresponde à realidade. Neste sentido, uma vez que a privatização é constatada como algo que acarreta em evidência, não haverá como revertê-la ou seria inútil se opor a ela.

Por meio do interdiscurso com a função da arte plástica e da representação de uma privada decorada, ela é atrelada à ordem da manipulação para atender a determinada necessidade que, no caso da charge, trata-se de convencer que privatizar estatais é algo positivo e que se pode admirar, assim como é possível contemplar a arte. De todo modo, a arte plástica, interdiscursivamente e tomada com o viés da ironia por Millôr, tem a ver com a questão de envolver e ludibriar quem quer que seja para pensar que a privatização é vantajosa, necessária e positiva em seus arranjos.

Todavia, Millôr, ao estabelecer relação com a arte plástica, provoca efeitos de sentido que levantam aspectos reais do quanto à privatização é falaciosa, pois, apesar da aparência bonita e promissora, na realidade, pelo feitio sarcástico da charge, ela é o contrário. Com isso, assim como a arte ornamenta e torna belo e atraente aos olhos, também há o empenho dos que estão no poder para adornar a privatização das instituições públicas com discursos afirmativos e promessas de melhorias, a fim de conquistar o modo de pensar das pessoas e convencê-las de que privatizar é uma ação nobre e necessária.

O significante 'privatização' é, ironicamente, atrelado ao significante 'privada', enquanto imagem e referente da construção do sentido. Deste modo, o trocadilho entre os significantes imageticamente constrói a imagem de um vaso sanitário: não qualquer vaso, mas um vaso ornamentado, atraente aos olhos, sedutor e esteticamente esculpido, para criar a ilusão ou a projeção dos anseios de quem quer convencer pela aparência. Este vaso sanitário, 


\section{$=$ TRAMA $=$}

embora sob a atividade da arte estética, remonta para o que ele realmente serve, ou seja, à sua função receptora de excrementos. A privada representa o lugar onde o ser humano deve evacuar e, por extensão, é análoga à ação de privatizar as instituições estatais; se comparada ao ato de excretar, em outras palavras, ela remete ao fato de que não se trata de algo aproveitável para a nação e para o povo, sendo que qualquer indício positivo de privatizar uma instituição pública não passa de mera construção manipuladora para seduzir e iludir os cidadãos de que é algo bom e belo, como a imagem do vaso sanitário pintado na charge.

A estética, como mecanismo de significação (Pêcheux, 1997), cria meios de regular as normas do que é belo na dinâmica das relações sociais. Millôr, ao se utilizar da imagem de uma privada ornamentada, cria um processo interdiscursivo com fenômenos sociais que perpassam os valores construídos esteticamente, o que sugere atrelar a privatização à influência estética que permeia as relações humanas e que consolida um imaginário do que é material e tangível, significando na construção dos sentidos da história e da vida de cada sujeito, de acordo com a inscrição em uma dada formação discursiva.

Quanto ao estudo do belo e do conceito e da concepção de beleza, há uma relação intrínseca entre a estética da arte e a relação humana, no que tange à evocação de emoções, juízos e ideias. Isso quer dizer que são despertadas no ser humano as mais variadas sensações e experiências, quando ele se depara com a experiência estética e o teor do que é belo para a projeção de si e da realidade. Acerca deste fio interdiscursivo com a estética, sob o olhar amplo de sua definição e das várias possibilidades de se pensar, a estética, enquanto complexo mecanismo de significação, especialmente no que concebeu a filosofia, recorre-se ao um excerto que abrange a não delimitação do que é a estética e do quão amplo são os efeitos de sentido que ela pode trazer à tona:

O Dictionnaire Historique et Critique de la Philosophie de A. Lalande (1980) define-a como a ciência que tem por objeto o juízo da apreciação que se aplica à distinção do belo e do feio, mas o Vocabulaire de l'Esthétique (1990) descreve-a como a filosofia e (a) ciência da arte; mais consensuais, Historisches Wörterbuch der Philosophie (1971), Enciclopaedia Filosofica (1967) e Academic American Encyclopaedia (1993) definem-na como o ramo da filosofia que trata das artes e da beleza. Se considerarmos as definições que dela nos dão os filósofos, também encontramos desacordos. Assim, Baumgarten definiu-a como ciência do mundo sensível do conhecimento de um objecto (Méditations, 1735), enquanto Hegel faz dela a filosofia da arte (Cours d'Esthétique, 1818 -1830). A esta confusão junta-se o sentido veiculado pela origem do termo: estética vem da palavra grega aisthêsis que designa simultaneamente a faculdade e o acto de sentir (a sensação e a percepção), e esta etimologia parece designar a estética como o estudo dos factos de sensibilidade no sentido lato (os aisthêta) por oposição aos factos de inteligência (os noêta). A estética será crítica do gosto, teoria do belo, ciência do sentir, filosofia da arte? Desta cacofonia de definições, sobressaem dois pontos. A estética é uma reflexão sobre um campo de objectos dominado pelos termos belo, sensível e arte. Cada um destes termos encerra e implica outros e estas séries cruzam-se [...] em diversos pontos: belo abre-se para o conjunto das propriedades estéticas; sensível remete para sentir, ressentir, imaginar e também para o gosto, para as qualidades sensíveis, para as imagens, para os afectos, etc.; arte abre-se para a criação, imitação, génio, inspiração, valor artístico, etc (HUGON, 2009, p. 7-8).

No fato de Millôr usar a imagem de uma privada com representação da arte enquanto estética, em uma análise consoante à citação acima de como a estética pode ser compreendida, percebe-se que a relação interdiscursiva está para o fato de que a estética constrói simbolicamente o pensamento humano e molda a sua maneira de interagir com o mundo, sob uma perspectiva de verdade, uma vez que está atrelada às sensações e percepções da vida. No tocante à charge, ao produzir a imagem estética enquanto porta-voz 


\section{$=$ TRAMA $=$}

do belo, do sensível e da arte, como se pode atrelar à citação, Millôr incorre no poder que a estética tem para fabricar pensamentos e ideias apelando para o sensivel e o belo, a fim de forjar a ideia de que a privatização é algo sedutor, por assim dizer; tal deslumbramento pela arte estética faz alusão, a partir do que se pode depreender da charge, aos discursos dos poderosos que tendem falar a partir de uma formação discursiva que apresenta e fomenta ações para privatizar instituições públicas como algo positivo, bom e necessário, visto que é do interesse dos que estão no comando da nação.

O contraste dos homens caricatos em relação à imagem da privada remete aos efeitos de sentido de que a privatização é proporcionalmente maior que as pessoas, isto é, tem uma força para se estabelecer como superior ao que podem os cidadãos intervir ou contê-la. Esta significação se dá pela forma com que Millôr apresenta as imagens na charge, pois as dispõe em desproporção de tamanho e enfatiza a discrepância do que pode um cidadão comum frente ao caráter monumental da privatização. Também é possível estabelecer uma relação entre o quanto às decisões dos que estão no poder é proporcionalmente maior do que dos demais, restando para estes, conforme a charge traz em um dos enunciados, considerar que "a privatização é para valer", como quem ocupa o lugar de mero expectador e só lhe cabe aceitar. Nesse aspecto, as condições de produção e o lugar social ocupado por cada sujeito é determinante na produção discursiva. Sobre isso, Pêcheux (1990, p. 77) teoriza o seguinte:

Um discurso é sempre pronunciado a partir de condições de produção dadas: por exemplo, o deputado pertence a um partido político que participa do governo ou a um partido da oposição; é porta-voz de tal ou tal grupo que representa tal ou tal interesse, ou então está "isolado" etc. Ele está, pois, bem ou mal, situado no interior de relações de força existentes entre os elementos antagonistas de um campo político dado: o que diz, o que anuncia, promete ou denuncia não tem o mesmo estatuto conforme o lugar que ele ocupa.

As condições de produção é que delimitam o dizer e os efeitos de sentido que podem ser construídos a partir desse dizer, sendo que cada sujeito do discurso se pronuncia a partir da formação discursiva, a qual trata da materialização da ideologia no discurso (Pêcheux, 1997), em que está inscrito, com os respectivos atravessamentos ideológicos. Na charge, o enunciado dos homens caricatos, representando uma conversa entre cidadãos, caracteriza o que pode ser dito por pessoas que ocupam determinado lugar social, como aponta a tese de Pêcheux para o fato de que o discurso emana do lugar social que o sujeito ocupa e é regido pelas relações de força inerente às posições de cada um. Deste modo, o discurso sobre a privatização por parte dos governantes que visam lograr vantagens é de apologia, visto que o lugar social que o ocupam é de quem pode ser privilegiado com tal ação, diferentemente do discurso dos cidadãos que enunciam dentro daquilo que the é permitido, uma vez que não tomam decisões governamentais, tampouco decisões acerca da privatização, pois ocupam um lugar social de aceitação das ações dos governantes.

No enunciado que aparece com o autorretrato caricato de Millôr, como quem espia para uma realidade conjuntural da política de privatização no Brasil, tem-se: 


\section{$=$ TRAMA $=$}

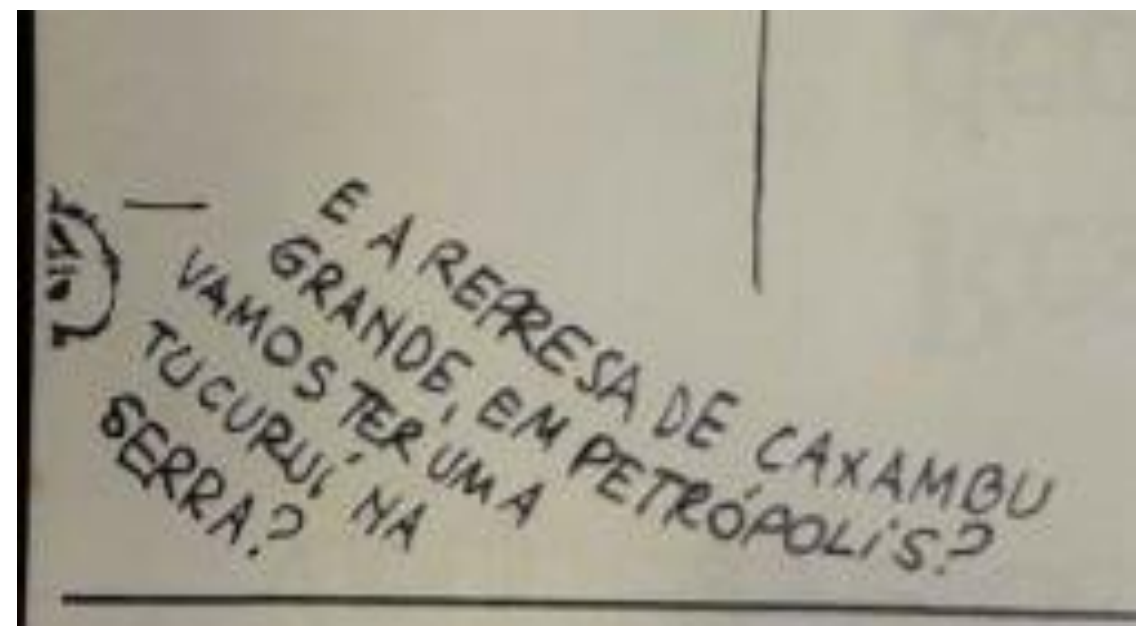

O enunciado da charge acima diz: "e a represa de Caxambu Grande, em Petrópolis? Vamos ter uma Tucuruí na Serra?" A represa de Caxambu Grande citada por Millôr fica no bairro Caxambu, na cidade de Petrópolis, localizada na região serrana do estado do Rio de Janeiro, trata-se de uma barragem para abastecimento de água potável da cidade. Na época em que Millôr produziu a charge, a represa era administrada pelo poder público, todavia, a partir de 1997, passou, por concessão do governo municipal de Petrópolis, a ser gerida pela iniciativa privada. Tal incidência corrobora o conteúdo da charge que, discursivamente, apresenta a questão da privatização com o sarcasmo de que é "pintado" ou retratado como algo belo, por conseguinte, bom.

Ao indagar "Vamos ter uma Tucuruí na Serra?", Millôr faz menção a uma das maiores usinas hidrelétricas brasileiras, localizada no município de Tucuruí, no estado do Pará. Em comparação com a represa de Caxambu, a barragem de Tucuruí é expressivamente maior. A pergunta do enunciado é provocativa, uma vez que o fluxo de água que abastece as barragens é de rios muito diferentes em tamanhos, o que remete à reflexão da ironia de que para algo ser grande e promissor deve ser gerido por uma empresa privada, já que a gestão pública não dá conta de fazer o seu trabalho de administração de forma eficaz. Assim, Millôr constrói efeitos de sentido que colocam a privatização como solução dos problemas que, na verdade, são problemas de governabilidade.

A charge recorda o interdiscurso da estética enquanto imagem que se cria e que pode ser sedutora e atraente aos olhos, mas também pode trazer em si a ilusão de algo ou daquilo que vem de encontro à realidade. Millôr, ao criar a imagem de um vaso sanitário ornamentado artisticamente, utiliza-se da ironia e elabora seu discurso para expor a inverdade de que a privatização é boa e bela. Porém, ao desenhar a privada proporcionalmente maior do que os homens caricatos, ele o faz com a evidência de que a privatização é mais poderosa que o cidadão comum. Nesse ínterim, o trocadilho entre os significantes "privatização" e a "privada" deixa claro que o governo, na condição de quem quer lucrar com a venda de estatais, dá a entender que privatizar algo é bom para a nação, quando, não passa de uma tentativa de dissimular a verdade, que implicaria em danos financeiros ao Estado e, consequentemente, ao povo que financiou, via impostos, cada instituição pública.

\section{CONSIDERAÇÕES FINAIS}

Por meio das análises, procurou-se olhar para os discursos de Millôr, levando-se em conta o alicerce da Teoria do Discurso para ponderar acerca de cada charge do corpus. Considerando que os discursos de Millôr constroem significados a partir de seus 


\section{$=$ TRAMA $=$}

atravessamentos ideológicos. Isto também vale, de certo modo, para o analista do discurso, que também está cativo dos efeitos de sentido concebidos sob o espectro do seu lugar social e da sua posição sujeito. São sempre hipóteses de produção de sentidos, parciais, no que se refere à ideologia constitutiva do sujeito, e ambivalentes na condição polissêmica da língua.

Percebeu-se, pela análise do corpus, a ocorrência de um movimento parafrástico nas charges de Millôr, reiterando o discurso de crítica ao governo de Sarney. Os conceitos mobilizados da Teoria do Discurso deram conta de um ensaio que mostrou a complexa rede de significação entre o sujeito, a história e o dizer, que remonta a efeitos de sentido da relação que há entre o que é interior e exterior à pessoa que enuncia, na chamada alteridade do sujeito que não está fechado em si, mas que mantém correspondência com uma exterioridade que o constitui, a si e a seu discurso.

A relação interdiscursiva atrelada ao discurso de Millôr, no que tange às duas charges do corpus, extraídas do livro de Millôr Fernandes, foram o pivô das abordagens analíticas, uma vez que todo dizer é composto por outros dizeres retomados de momentos outros e de sujeitos outros para serem suscitados a significar no ato de enunciação de acordo com as condições de produção imanentes ao acontecimento discursivo. O humor é um mecanismo do discurso de Millôr, que se vale de ironia, sarcasmo e sátira e cujos enunciados e imagens caricatas foram concebidos para produzirem efeitos de sentidos de crítica à política da Nova República (1985 - 1990).

O discurso de Millôr advém do lugar social e da posição-sujeito de jornalista que ele ocupa, a qual é correspondente à inscrição na formação discursiva que se contraidentifica com as ações do governo. Graças à Análise do Discurso, foi possível estabelecer conexão entre o dizer de Millôr com seus atravessamentos ideológicos, dos quais ele é porta-voz, e o processo de produção de sentido atrelado à materialidade discursiva, à subjetividade do sujeito, à historicidade e à interdiscursividade que, juntos, constituem o dito e sua significação.

O discurso de Millôr, embora fale das condições de produção do passado, é também atual, pois manifesta a recorrente corrupção na política do Brasil, o que remete a ponderar sobre a percepção de que a corrupção é cíclica na nação brasileira, acarretando prejuízos para a população como um todo. Todo o dizer de Millôr cerca o inquestionável mal da corrupção, no que se refere aos crimes cometidos por quem ocupa altos cargos na política brasileira e que se utiliza da sua posição para angariar privilégios, ao invés de executar o trabalho que the foi conferido pelo povo, ou seja, o papel de administrar em prol da nação, dos mais necessitados, e não em favor de benesses ilegais entre poderosos da elite.

Além de fazer parte do passado, a corrupção ainda é um assunto da atualidade. $\mathrm{O}$ recorte que compõe o corpus desta pesquisa mostra que trata de um tema antigo e contemporâneo da história da nação brasileira, que diz respeito aos abusos dos que governam. Com um olhar atento para o discurso de Millôr, foi possível captar os efeitos de sentido que interpelam a política de ontem e de hoje. Depreende-se que o dizer de cada charge atesta o quão ineficaz é a gestão das instituições públicas por parte daqueles que estão no poder que articulam para interesses próprios e ganhos ilegais por meio do exercício da função, o que traz à tona as implicações de danos irreversíveis à sociedade brasileira que é vítima de uma corrupção histórica, sistêmica e endêmica.

Ao analisar as possibilidades de efeitos de sentido produzidos pelos discursos presentes no humor político de Millôr acerca da Nova República (1985 - 1990), especificamente sob o recorte das duas charges de seu livro intitulado "Diário da Nova República - Vol. 2", a partir de uma relação interdiscursiva com a devida recuperação do jádito, é possível reconhecer que existe margem de fronteira entre o que deveria ser um fazer político honesto e a corrupção no Brasil, a qual vem do passado e permanece até os dias de 


\section{$=$ TRAMA $=$}

hoje. Isso implica dizer que rememorar Millôr, enquanto sujeito porta-voz de um discurso de crítica à corrupção, é também ler o presente cenário do político do Brasil.

Os discursos do autor, ironicamente articulados pelo viés do humor e da incidência do interdiscurso, tratam com acidez assuntos sérios e críticos em relação à política. Millôr dá a tônica da realidade da sociedade brasileira no período Pós-Ditadura, realizando produções discursivas que incitam pensar sobre o que faz do Brasil um país em que, historicamente, persiste a corrupção sem que tenha havido até então a aniquilação ou a inibição de ações criminosas por parte de poderosos governantes, que configuram as épocas passadas e a época atual. Portanto, há uma linha fronteiriça na política do Brasil, a que separa uma política que deveria estar a serviço do povo de uma política que serve aos que estão no poderio.

Depreende-se que o discurso de Millôr, nas charges analisadas, é porta-voz daqueles que são explorados pelo governo e fala em nome de um povo que depositou convicção na administração de Sarney, inclusive sob um governo intitulado como Nova República, um nome que suscita mudanças, mas que não fez jus à denominação. Assim como a Nova República de 1985 prometia revolucionar a política brasileira, mas que não passou de uma política de poderosos para poderosos, também o Brasil de hoje, que ansiou por um salvador, continua submergido pelas mesmas debilidades institucionais e pela grave deficiência da gestão pública, que insiste em submeter os cidadãos contribuintes a prejuízos frequentes. O país continua, neste momento, nas mãos de governantes que se empenham em esmagar a classe trabalhadora obrigando-a a pagar impostos altíssimos sem retorno na qualidade de serviços públicos e à dignidade, concentrando benefícios apenas entre os que estão no poder.

Para finalizar, propõe-se fazer uma analogia entre o dizer de Millôr e o quadro contemporâneo da política brasileira. Constata-se que os efeitos de sentido provocados pelo discurso de Millôr são contumazes e atuais, pois não se trata de mera coincidência essa relação entre os níveis de corrupção que atravessaram o tempo e a cultura de benesses dos governantes, como se fosse uma tradição e um revezamento entre poderosos governantes que continuam a extorquir o povo subjugado e a viver prestigiosamente com o dinheiro de uma população que confiou neles. Neste sentido, que é preciso um manejo anticorrupção por parte dos cidadãos e em especial por parte da justiça do Brasil para tentar liquidar a corrupção, que é um problema que impacta o desenvolvimento, afeta o acesso e a qualidade da prestação dos serviços públicos, afligindo a parcela da população mais pobre e vulnerável, por atacar os direitos dos cidadãos brasileiros que pagam impostos e sustentam o país.

\section{REFERÊNCIAS}

FERNANDES, Millôr. Diário da Nova República - Vol. 2. São Paulo - SP: L\&PM Editores S/A, 1988.

HUGON, Carole Talon-. A estética: história e teorias. [tradução António Maia da Rocha]. Editora Papelmunde, SMG, Ltda. 1a edição, Lisboa, 2009.

PÊCHEUX, Michel. A Análise do Discurso: Três Épocas. (Trad. De J. de A. Romualdo). In: GADET, F. \& HAK, T. (orgs.) Por uma análise automática do discurso: uma introdução à obra de Michel Pêcheux. Campinas: Editora da UNICAMP, pp. 311318, 1997.

. Delimitações, inversões, deslocamentos. In: (Trad. José Horta Nunes). Cadernos de Estudos Linguísticos, Campinas, São Paulo, n. 19, p. 7-24, jul,/dez/1990.

Papel da memória. In: Papel da memória/Pierre Achard... [et al.] tradução e introdução: José Horta Nunes - 2a Edição, Campinas, SP: Pontes Editores, 2007.

SUPER INTERESSANTE. Existiu realmente o Tio Sam, que simboliza os Estados Unidos? Redação Mundo Estranho, 2011. Disponivel em: <https://super.abril.com.br/mundo-estranho/existiu-realmente-o-tio-sam-que-simboliza-os-estados-unidos/>. Acesso em: 24 de ago. 2018.

. No tempo dos corsários e piratas. História, 2016. Disponível em: <https://super.abril.com.br/historia/no-tempo-doscorsarios-e-piratas/>. acesso em: 23 de jun. 2019.

UOL, Aventuras na História. Grandes Navegações, 2019. Disponível em:

$<$ https://aventurasnahistoria.uol.com.br/noticias/reportagem/bartolomeu-dias-cabo-tormentas-historia.phtml>. Acesso em: 29 de jun. 2019 